\title{
A note on Ćirić type nonunique fixed point theorems
}

\author{
Erdal Karapınar ${ }^{1,2^{*}}$ (D) and Ravi P Agarwal ${ }^{3}$ \\ Dedicated to memory of Prof. L.Ćirić.
}

"Correspondence:
erdalkarapinar@yahoo.com
'Department of Mathematics,
Atilim University, Incek, Ankara,
06836, Turkey
${ }^{2}$ Nonlinear Analysis and Applied
Mathematics (NAAM) Research
Group, King Abdulaziz University,
Jeddah, 21589, Saudi Arabia
Full list of author information is
available at the end of the article

available at the end of the article

\begin{abstract}
In this paper, we suggest some nonunique fixed results in the setting of various abstract spaces. The proposed results extend, generalize and unify many existing results in the corresponding literature.
\end{abstract}

MSC: 46T99; 47H10; 54H25

Keywords: abstract metric space; nonunique fixed point; self-mappings

\section{Introduction and preliminaries}

In 1974, Ćirić [1] introduced the notion of nonunique fixed point and proposed criteria for certain operators which possess nonunique fixed points. Inspired by this pioneering work, a number of authors reported nonunique fixed point for the operators that provide different conditions, see e.g. [1-6].

In 2000, Branciari [7] introduced a new distance function that is obtained by replacing the quadrilateral inequality with the triangle inequality in the axioms of the standard metric notion. In what follows, we recall the notion of a Branciari metric space.

Definition 1 (see e.g. [8]) Let $X$ be a nonempty set, and let $\rho: X \times X \longrightarrow[0, \infty)$ satisfy the following conditions for all $x, y \in X$ and all distinct $u, v \in X \backslash\{x, y\}$ :
(b1) $\rho(x, y)=0$ if and only if $x=y \quad$ (indistancy),
(b2) $\rho(x, y)=\rho(y, x) \quad$ (symmetry),
(b3) $\rho(x, y) \leq \rho(x, u)+\rho(u, v)+\rho(v, y) \quad$ (quadrilateral inequality).

Then the map $\rho$ is called a Branciari metric (or rectangular metric, or generalized metric). The pair $(X, \rho)$ is called a Branciari metric space and abbreviated as BMS.

In some sources, BMS was called 'generalized metric space'. On the other hand, in the literature, the words 'generalized metric' space have been used for several different extensions of the notion of metric (see e.g. [7, 9-23]). For this reason, we prefer to use 'Branciari metric' to avoid the confusion.

(c) The Author(s) 2017. This article is distributed under the terms of the Creative Commons Attribution 4.0 International License (http://creativecommons.org/licenses/by/4.0/), which permits unrestricted use, distribution, and reproduction in any medium, provided you give appropriate credit to the original author(s) and the source, provide a link to the Creative Commons license, and indicate if changes were made. 
From now onward, the set of positive integers and the set of nonnegative integers will be denoted by $\mathbb{N}$ and $\mathbb{N}_{0}$, respectively. Further, the symbols $\mathbb{R}, \mathbb{R}^{+}$and $\mathbb{R}_{0}^{+}$indicate the real numbers, positive real numbers and nonnegative real numbers, respectively.

Notice that the concepts of open ball and closed ball are defined on BMS as the corresponding notions in the setting of the standard metric space. Hence, there is a proper topology on BMS $(X, \rho)$.

Definition 2 (see e.g. [8])

(1) A sequence $\left\{x_{n}\right\}$ in a BMS $(X, \rho)$ is BMS convergent to a limit $x$ if and only if $\rho\left(x_{n}, x\right) \rightarrow 0$ as $n \rightarrow \infty$.

(2) A sequence $\left\{x_{n}\right\}$ in a BMS $(X, \rho)$ is BMS Cauchy if and only if, for every $\varepsilon>0$, there exists a positive integer $N(\varepsilon)$ such that $\rho\left(x_{n}, x_{m}\right)<\varepsilon$ for all $n>m>N(\varepsilon)$.

(3) A BMS $(X, \rho)$ is called complete if every BMS Cauchy sequence in $X$ is BMS convergent.

(4) A mapping $T:(X, \rho) \rightarrow(X, \rho)$ is continuous if, for any sequence $\left\{x_{n}\right\}$ in $X$ such that $\rho\left(x_{n}, x\right) \rightarrow 0$ as $n \rightarrow \infty$, we have $\rho\left(T x_{n}, T x\right) \rightarrow 0$ as $n \rightarrow \infty$.

On the other hand, the topology of BMS $(X, \rho)$ brings some difficulties. We state the following example to illustrate the possible handicaps.

Example 3 (cf. [16, 24]) Let $Y=\left\{\frac{1}{n^{2}+1}: n \in \mathbb{N}\right\}$ and $Z=\left\{0, z_{1}, z_{2}, z_{3}\right\}$, where $z_{1}, z_{2}, z_{3}$ are distinct real numbers such that $z_{1}, z_{2}, z_{3}>2$. Set $X=Y \cup Z$ and consider the function $\rho$ : $X \times X \rightarrow[0, \infty)$ in the following way:

$$
\rho(x, y)= \begin{cases}0 & \text { if } x=y, \\ 1 & \text { if } x \neq y \text { and }[\{x, y\} \subset Y \text { or }\{x, y\} \subset Z], \\ y & \text { if } x \in Y, y \in Z .\end{cases}
$$

We have $\rho(y, z)=\rho(z, y)=z$ whenever $y \in Y$ and $z \in Z$; and $(X, \rho)$ is a complete BMS. Notice that statements $(P 1)-(P 4)$ are fulfilled:

(p1) Since $\lim _{n \rightarrow \infty} \frac{1}{n^{2}+1}=0$, we have $\lim _{n \rightarrow \infty} \rho\left(\frac{1}{n^{2}+1}, \frac{1}{5}\right) \neq \rho\left(0, \frac{1}{5}\right)$. Thus, the function $\rho$ is not continuous;

(p2) There is no $r>0$ such that $B_{r}(0) \cap B_{r}\left(z_{i}\right)=\emptyset$ for $i=1,2,3$, and hence it is not Hausdorff; (p3) It is clear that the ball $B_{\frac{3}{5}}\left(\frac{1}{5}\right)=\left\{0, \frac{1}{5}, z_{1}, z_{2}, z_{3}\right\}$ since there is no $r>0$ such that $B_{r}(0) \subset$ $B_{\frac{3}{5}}\left(\frac{1}{5}\right)$, that is, open balls may not be an open set;

(p4) The sequence $\left\{\frac{1}{n^{2}+1}: n \in \mathbb{N}\right\}$ converges to $0, z_{1}, z_{2}, z_{3}$, and hence it is not Cauchy.

Despite a high similarity rate between the definitions of topological notions in BMS and in standard metric space, there are significant differences between their topologies due to the diversity between the quadrilateral inequality and the triangle inequality. For being more clear, we can express the variations as follows:

(p1) Branciari metric is not necessarily continuous (see e.g. Example 3);

(p2) BMS is not necessarily Hausdorff (limit is not necessarily unique) (see e.g. Example 3);

(p3) open ball need not be an open set (see e.g. Example 3);

(p4) a convergent sequence in BMS needs not be Cauchy (see e.g. Example 3);

$(p 5)$ the mentioned topologies are incompatible (see e.g. Example 7 in [23]). 
Lemma 4 (see e.g. $[15,16])$ Let $(X, \rho)$ be a BMS, and let $\left\{x_{n}\right\}$ be a Cauchy sequence in $X$ such that $x_{m} \neq x_{n}$ whenever $m \neq n$. Then the sequence $\left\{x_{n}\right\}$ can converge to at most one point.

Later, regarding the well-known $b$-metric defined by Czerwik [25], the notion of Branciari metric is refined as $b$-Branciari metric (see e.g. [26]).

Definition 5 Let $X$ be a nonempty set, and let $d: X \times X \rightarrow[0, \infty)$ satisfy the following conditions for all $x, y \in X$ and all distinct $u, v \in X \backslash\{x, y\}$ :

(b1) $d(x, y)=0 \quad$ if and only if $\quad x=y \quad$ (indistancy),

(b2) $d(x, y)=d(y, x) \quad($ symmetry),

(b3) $d(x, y) \leq s[d(x, u)+d(u, v)+d(v, y)] \quad$ (modified quadrilateral inequality).

Then the map $d$ is called a $b$-Branciari metric (or rectangular metric, or generalized metric). The pair $(X, d)$ is called a $b$-Branciari metric space and abbreviated as ' $b$-BMS'.

Analogously, one can state the topological concepts for $b$-BMS (see e.g. [26]).

\section{Definition 6}

(1) A sequence $\left\{x_{n}\right\}$ in a $b$-BMS $(X, \rho)$ is $b$-BMS convergent to a limit $x$ if and only if $\rho\left(x_{n}, x\right) \rightarrow 0$ as $n \rightarrow \infty$.

(2) A sequence $\left\{x_{n}\right\}$ in a $b$-BMS $(X, \rho)$ is $b$-BMS Cauchy if and only if, for every $\varepsilon>0$, there exists a positive integer $N(\varepsilon)$ such that $\rho\left(x_{n}, x_{m}\right)<\varepsilon$ for all $n>m>N(\varepsilon)$.

(3) A $b$-BMS $(X, \rho)$ is called complete if every $b$-BMS Cauchy sequence in $X$ is $b$-BMS convergent.

(4) A mapping $T:(X, \rho) \rightarrow(X, \rho)$ is continuous if, for any sequence $\left\{x_{n}\right\}$ in $X$ such that $\rho\left(x_{n}, x\right) \rightarrow 0$ as $n \rightarrow \infty$, we have $\rho\left(T x_{n}, T x\right) \rightarrow 0$ as $n \rightarrow \infty$.

As in the discussion on the topology of BMS, the topology of $b$-BMS has the same difficulties (p1)-(p5) above. Since these problems arise from the topology of BMS, Example 3 can be adopted for $b$-BMS to illustrate that the same problems hold for the topology of $b$-BMS (see e.g. [26]).

Inspired by the corresponding Lemma 4, we propose the following.

Lemma 7 Let $(X, d)$ be a $b$-BMS, and let $\left\{x_{n}\right\}$ be a Cauchy sequence in $X$ such that $x_{m} \neq x_{n}$ whenever $m \neq n$. Then the sequence $\left\{x_{n}\right\}$ can converge to at most one point.

Proof

Suppose, on the contrary, that $\left\{x_{n}\right\}$ is a Cauchy sequence which converges to both $x$ and $y$, where $x \neq y$. Thus, for any $\varepsilon$, there exists $N \in \mathbb{N}$ such that

$$
d\left(x, x_{n}\right)<\frac{\varepsilon}{3 s}, \quad d\left(x_{n}, x_{m}\right)<\frac{\varepsilon}{3 s} \quad \text { and } \quad d\left(x_{m}, y\right)<\frac{\varepsilon}{3 s}
$$

for all $n, m>N$. 
Now, by using the modified quadrilateral inequality, we get

$$
d(x, y) \leq s\left[d\left(x, x_{n}\right)+d\left(x_{n}, x_{m}\right)+d\left(x_{m}, y\right)\right]<\varepsilon
$$

Thus, one can get $d(x, y)=0$ and hence $x=y$, a contradiction. Thus, under the axiom, the given sequence has a unique limit point.

Let $\Psi$ be a family of increasing mappings $\psi:[0, \infty) \rightarrow[0, \infty)$ satisfying $\psi^{n}(t) \rightarrow 0$, $n \rightarrow \infty$ for any $t \in[0, \infty)$. In the literature such functions are called comparison functions (see e.g. [27]). The basic example of such mappings is $\psi(t)=\frac{k t}{n}$, where $k \in[0,1)$ and $n \in$ $\{2,3, \ldots\}$.

Lemma 8 (see e.g. [27]) If $\psi \in \Psi$, then the following hold:

(i) $\psi$ is continuous at 0 ;

(ii) $\psi(t)<t$ for any $t \in \mathbb{R}^{+}$.

In this manuscript, we investigate some nonunique fixed point results in the context of $b$-BMS. Our results extend and generalize several results in the corresponding literature.

\section{Nonunique fixed points on $b$-BMS}

First, we shall give the analog of the crucial topological notions, orbitally continuous and orbitally complete, in the context of $b$-BMS.

Definition 9 (see [1]) Let $(X, d)$ be a $b$-BMS and $T$ be a self-map of $X$.

(1) $T$ is called orbitally continuous if

$$
\lim _{i \rightarrow \infty} T^{n_{i}} x=z
$$

implies

$$
\lim _{i \rightarrow \infty} T T^{n_{i}} x=T z
$$

for each $x \in X$.

(2) $(X, d)$ is called orbitally complete if every Cauchy sequence of type $\left\{T^{n_{i}} x\right\}_{i \in \mathbb{N}}$ converges with respect to $\tau_{d}$.

A point $z$ is said to be a periodic point of a function $T$ of period $m$ if $T^{m}(z)=z$, where $T^{0}(x)=x$ and $T^{m}(x)$ is defined recursively by $T^{m}(x)=T\left(T^{m-1}(x)\right)$.

\section{1 Ćirić type nonunique fixed point results}

Theorem 10 Let $T$ be an orbitally continuous self-map on the T-orbitally complete b$B M S(X, d)$ with $s \geq 1$. If there is $\psi \in \Psi$ such that

$$
\min \{d(T x, T y), d(x, T x), d(y, T y)\}-\min \{d(x, T y), d(T x, y)\} \leq \psi(d(x, y))
$$

for all $x, y \in X$, then, for each $x_{0} \in X$, the sequence $\left\{T^{n} x_{0}\right\}_{n \in \mathbb{N}}$ converges to a fixed point of $T$. 
Proof For an arbitrary $x \in X$, we shall construct an iterative sequence $\left\{x_{n}\right\}$ as follows:

$$
x_{0}:=x \quad \text { and } \quad x_{n}=T x_{n-1} \quad \text { for all } n \in \mathbb{N} \text {. }
$$

We suppose that

$$
x_{n} \neq x_{n-1} \quad \text { for all } n \in \mathbb{N} \text {. }
$$

Indeed, if for some $n \in \mathbb{N}$ we have the inequality $x_{n}=T x_{n-1}=x_{n-1}$, then the proof is completed.

By substituting $x=x_{n-1}$ and $y=x_{n}$ in inequality (2.3), we derive that

$$
\begin{aligned}
& \min \left\{d\left(T x_{n-1}, T x_{n}\right), d\left(x_{n-1}, T x_{n-1}\right), d\left(x_{n}, T x_{n}\right)\right\}-\min \left\{d\left(x_{n-1}, T x_{n}\right), d\left(T x_{n-1}, x_{n}\right)\right\} \\
& \quad \leq \psi\left(d\left(x_{n-1}, x_{n}\right)\right) .
\end{aligned}
$$

It implies that

$$
\min \left\{d\left(x_{n}, x_{n+1}\right), d\left(x_{n}, x_{n-1}\right)\right\} \leq \psi\left(d\left(x_{n-1}, x_{n}\right)\right) .
$$

Since $\psi(t)<t$ for all $t>0$, the case $d\left(x_{n}, x_{n-1}\right) \leq \psi\left(d\left(x_{n-1}, x_{n}\right)\right)$ is impossible. Thus, we have

$$
d\left(x_{n}, x_{n+1}\right) \leq \psi\left(d\left(x_{n-1}, x_{n}\right)\right)<d\left(x_{n-1}, x_{n}\right) .
$$

Iteratively, we find that

$$
d\left(x_{n}, x_{n+1}\right) \leq \psi\left(d\left(x_{n-1}, x_{n}\right)\right) \leq \psi^{2}\left(d\left(x_{n-2}, x_{n-1}\right)\right) \leq \cdots \leq \psi^{n}\left(d\left(x_{0}, x_{1}\right)\right)
$$

On account of (2.8), we also observe that the sequence $\left\{d\left(x_{n}, x_{n+1}\right)\right\}$ is nonincreasing.

Since $\psi^{n}(t) \rightarrow 0, n \rightarrow \infty$ for any $t \in[0, \infty)$, and $\psi(t)<t$, and regarding the Archimedean property, there exist a real number $q \in[0,1)$ and a natural number $M$ such that

$$
\psi^{k}(t) \leq q^{k} \cdot t \quad \text { and } s \cdot q^{k}<1 \text { for each } n>M
$$

We shall show that the sequence $\left\{x_{n}\right\}$ has no periodic point, that is,

$$
x_{n} \neq x_{n+k} \quad \text { for all } k \in \mathbb{N} \text { and for all } n \in \mathbb{N}_{0} \text {. }
$$

Actually, if $x_{n}=x_{n+k}$ for some $n \in \mathbb{N}_{0}$ and $k \in \mathbb{N}$, we find $x_{n+1}=T x_{n}=T x_{n+k}=x_{n+k+1}$. Keeping inequality (2.8) in mind, by utilizing (2.3), we derive that

$$
\begin{aligned}
d\left(x_{n}, x_{n+1}\right)= & \min \left\{d\left(T x_{n-1}, T x_{n}\right), d\left(x_{n-1}, T x_{n-1}\right), d\left(x_{n}, T x_{n}\right)\right\} \\
& -\min \left\{d\left(x_{n-1}, T x_{n}\right), d\left(T x_{n-1}, x_{n}\right)\right\} \\
= & \min \left\{d\left(T x_{n+k-1}, T x_{n+k}\right), d\left(x_{n+k-1}, T x_{n+k-1}\right), d\left(x_{n}, T x_{n+k}\right)\right\} \\
& -\min \left\{d\left(x_{n+k-1}, T x_{n+k}\right), d\left(T x_{n+k-1}, x_{n+k}\right)\right\}
\end{aligned}
$$




$$
\begin{aligned}
& \leq \psi\left(d\left(x_{n+k-1}, x_{n+k}\right)\right) \\
& \leq \psi^{k-1}\left(d\left(x_{n}, x_{n+1}\right)\right)<d\left(x_{n}, x_{n+1}\right)
\end{aligned}
$$

a contradiction. Consequently, throughout the proof, we suppose that

$$
x_{n} \neq x_{m} \quad \text { for all distinct } n, m \in \mathbb{N} \text {. }
$$

Observe that $x_{n+k} \neq x_{m+k}$ for all distinct $n, m \in \mathbb{N}$ and $x_{n+k}, x_{m+k} \in X \backslash\left\{x_{n}, x_{m}\right\}$.

In what follows, we shall prove that the sequence $\left\{x_{n}\right\}$ is Cauchy. By using the modified quadrilateral inequality together with (2.9) and estimation (2.10), we have

$$
\begin{aligned}
d\left(x_{m}, x_{n}\right) & \leq s\left[d\left(x_{m}, x_{m+k}\right)+d\left(x_{m+k}, x_{n+k}\right)+d\left(x_{n+k}, x_{n}\right)\right] \\
& \leq s \psi^{m}\left(d\left(x_{0}, x_{k}\right)\right)+s \psi^{k}\left(d\left(x_{m}, x_{n}\right)\right)+s \psi^{n}\left(d\left(x_{k}, x_{0}\right)\right) \\
& \leq s \psi^{m}\left(d\left(x_{0}, x_{k}\right)\right)+s q^{k} \cdot d\left(x_{m}, x_{n}\right)+s \psi^{n}\left(d\left(x_{k}, x_{0}\right)\right) .
\end{aligned}
$$

After a routine calculation, we get that

$$
d\left(x_{m}, x_{n}\right) \leq \frac{s}{1-s q^{k}}\left[\psi^{m}\left(d\left(x_{0}, x_{k}\right)\right)+\psi^{n}\left(d\left(x_{k}, x_{0}\right)\right)\right]
$$

Since $\psi^{n}(t) \rightarrow 0, n \rightarrow \infty$, for any $t \in[0, \infty)$, the inequality above yields that $d\left(x_{m}, x_{n}\right) \rightarrow 0$ as $n, m \rightarrow \infty$. Hence, the sequence $\left\{x_{n}\right\}$ is Cauchy in $b$-BMS $(X, d)$.

On account of the $T$-orbital completeness, we conclude that there is $z \in X$ such that $x_{n} \rightarrow z$. Due to the orbital continuity of $T$, we conclude that $x_{n} \rightarrow T z$. Hence, by taking Lemma 7 into account, we find $z=T z$, which terminates the proof.

Corollary 11 Let $T$ be an orbitally continuous self-map on the T-orbitally complete b-BMS $(X, d)$ with $s \geq 1$. If there is $q \in[0,1)$ such that

$$
\min \{d(T x, T y), d(x, T x), d(y, T y)\}-\min \{d(x, T y), d(T x, y)\} \leq q d(x, y)
$$

for all $x, y \in X$, then for each $x_{0} \in X$ the sequence $\left\{T^{n} x_{0}\right\}_{n \in \mathbb{N}}$ converges to a fixed point of $T$.

Proof It is sufficient to take $\psi(t)=q t$, where $q \in[0,1)$, in Theorem 10 .

Corollary 12 Let $T$ be an orbitally continuous self-map on the T-orbitally complete BMS $(X, d)$ with $s \geq 1$. If there is $\psi \in \Psi$ such that

$$
\min \{d(T x, T y), d(x, T x), d(y, T y)\}-\min \{d(x, T y), d(T x, y)\} \leq \psi(d(x, y))
$$

for all $x, y \in X$, then for each $x_{0} \in X$ the sequence $\left\{T^{n} x_{0}\right\}_{n \in \mathbb{N}}$ converges to a fixed point of $T$.

Proof It is sufficient to take $s=1$ in Theorem 10 .

Corollary 13 Let $T$ be an orbitally continuous self-map on the T-orbitally complete BMS $(X, d)$ with $s \geq 1$. If there is $q \in[0,1)$ such that

$$
\min \{d(T x, T y), d(x, T x), d(y, T y)\}-\min \{d(x, T y), d(T x, y)\} \leq q d(x, y)
$$


for all $x, y \in X$, then for each $x_{0} \in X$ the sequence $\left\{T^{n} x_{0}\right\}_{n \in \mathbb{N}}$ converges to a fixed point of $T$.

Proof It is sufficient to take $\psi(t)=q t$, where $q \in[0,1)$, in Corollary 12 .

Example 14 Let $X=A \cup B$, where $A=\left\{a_{1}, a_{2}, a_{3}, a_{4}\right\}$ and $B=[1,2]$ with $A \cap B=\emptyset$ and each $a_{i}$ distinct from $a_{j}$, whenever $i \neq j$. Define $d: X \times X \rightarrow[0, \infty)$ such that $d(x, y)=d(y, x)$ for all $x \in X$,

$$
\begin{aligned}
& d\left(a_{1}, a_{3}\right)=1, \quad d\left(a_{1}, a_{2}\right)=d\left(a_{2}, a_{3}\right)=\frac{1}{4}, \\
& d\left(a_{1}, a_{4}\right)=d\left(a_{2}, a_{4}\right)=d\left(a_{3}, a_{4}\right)=\frac{1}{8}, \\
& d(a, b)=\frac{1}{16}, \quad \text { for all } a \in A, b \in B, \text { and } \\
& d(x, y)=|x-y|^{2} \quad \text { for any other case. }
\end{aligned}
$$

It is clear that $(X, d)$ forms a complete $b$-BMS $(X, d)$ with $s=2$. Note also that $(X, d)$ is not metric, $b$-metric and Branciari metric. Define a mapping $T: X \rightarrow X$ as

$$
f\left(a_{1}\right)=f\left(a_{2}\right)=a_{1} \quad \text { and } \quad f\left(a_{3}\right)=f\left(a_{4}\right)=a_{4} \quad \text { and } \quad f(b)=a_{1} \quad \text { for all } b \in B .
$$

It is clear that $T$ satisfies all the conditions of Theorem 10 for any choice of $\psi$ and $T$ has two distinct fixed points, namely, $a_{1}$ and $a_{3}$.

\section{2 Ćirić-Jotić type nonunique fixed point results [3]}

Theorem 15 Let $T$ be an orbitally continuous self-map on the T-orbitally complete $b$-BMS $(X, d)$. Suppose that there exist $\psi \in \Psi$ and $a \geq 0$ such that

$$
P(x, y)-a Q(x, y) \leq \psi(R(x, y))
$$

for all distinct $x, y \in X$, where

$$
\begin{aligned}
& P(x, y)=\min \left\{\begin{array}{c}
d(T x, T y), d(x, y), d(x, T x), d(y, T y), \frac{d(x, T x)[1+d(y, T y)]}{1+d(x, y)}, \\
\frac{d(y, T y)[1+d(x, T x)]}{1+d(x, y)}, \frac{\min \left\{d^{2}(T x, T y), d^{2}(x, T x), d^{2}(y, T y)\right\}}{\psi(d(x, y))}
\end{array}\right\}, \\
& Q(x, y)=\min \{d(x, T y), d(y, T x)\}, \\
& R(x, y)=\max \{d(x, y), d(x, T x)\} .
\end{aligned}
$$

Then, for each $x_{0} \in X$, the sequence $\left\{T^{n} x_{0}\right\}_{n \in \mathbb{N}}$ converges to a fixed point of $T$.

Proof As in Theorem 10, by starting from an arbitrary initial value $x_{0}:=x \in X$, we easily construct an iterative sequence $\left\{x_{n}=T x_{n-1}\right\}_{n \in \mathbb{N}}$ for which adjacent terms are distinct from each other, that is,

$$
x_{n} \neq x_{n-1} \quad \text { for all } n \in \mathbb{N} \text {. }
$$


Letting $x=x_{n-1}$ and $y=T x_{n-1}=x_{n}$ in inequality (2.18), we derive that

$$
P\left(x_{n-1}, x_{n}\right)-a Q\left(x_{n-1}, x_{n}\right) \leq \psi\left(R\left(x_{n-1}, x_{n}\right)\right)
$$

where

$$
\begin{aligned}
& Q\left(x_{n-1}, x_{n}\right)=\min \left\{d\left(x_{n-1}, x_{n+1}\right), d\left(x_{n}, x_{n}\right)\right\}=0, \\
& R\left(x_{n-1}, x_{n}\right)=\max \left\{d\left(x_{n-1}, x_{n}\right), d\left(x_{n-1}, x_{n}\right)\right\}=d\left(x_{n-1}, x_{n}\right)
\end{aligned}
$$

and

$$
\begin{aligned}
P\left(x_{n-1}, x_{n}\right) & =\min \left\{\begin{array}{c}
d\left(x_{n}, x_{n+1}\right), d\left(x_{n-1}, x_{n}\right), d\left(x_{n-1}, x_{n}\right), d\left(x_{n}, x_{n+1}\right), \frac{d\left(x_{n-1}, x_{n}\right)\left[1+d\left(x_{n}, x_{n+1}\right)\right]}{1+d\left(x_{n-1}, x_{n}\right)}, \\
\frac{d\left(x_{n}, x_{n+1}\right)\left[1+d\left(x_{n-1}, x_{n}\right)\right]}{1+d\left(x_{n-1}, x_{n}\right)}, \frac{\min \left\{d^{2}\left(x_{n}, x_{n+1}\right), d^{2}\left(x_{n-1}, x_{n}\right), d^{2}\left(x_{n}, x_{n+1}\right)\right\}}{\psi\left(d\left(x_{n-1}, x_{n}\right)\right)}
\end{array}\right\} \\
& =\min \left\{d\left(x_{n}, x_{n+1}\right), d\left(x_{n-1}, x_{n}\right), \frac{d\left(x_{n-1}, x_{n}\right)\left[1+d\left(x_{n}, x_{n+1}\right)\right]}{1+d\left(x_{n-1}, x_{n}\right)}, \frac{d^{2}\left(x_{n}, x_{n+1}\right)}{\psi\left(d\left(x_{n-1}, x_{n}\right)\right)}\right\} .
\end{aligned}
$$

We examine inequality (2.19) regarding the possible cases in $P\left(x_{n-1}, x_{n}\right)$. Notice that the case $P\left(x_{n-1}, x_{n}\right)=d\left(x_{n-1}, x_{n}\right)$ is impossible. Indeed, if it were the case, inequality (2.19) would turn into

$$
d\left(x_{n-1}, x_{n}\right) \leq \psi\left(d\left(x_{n-1}, x_{n}\right)\right)<d\left(x_{n-1}, x_{n}\right)
$$

since $\psi(t)<t$ for all $t>0$. Thus, we observe that

$$
d\left(x_{n}, x_{n+1}\right) \leq d\left(x_{n-1}, x_{n}\right)
$$

Consequently, inequality (2.19) yields the following three cases. If $P\left(x_{n-1}, x_{n}\right)=d\left(x_{n}, x_{n+1}\right)$ or $P\left(x_{n-1}, x_{n}\right)=\frac{d^{2}\left(x_{n}, x_{n+1}\right)}{\psi\left(d\left(x_{n-1}, x_{n}\right)\right)}$, then inequality (2.19) turns into

$$
d\left(x_{n}, x_{n+1}\right) \leq \psi\left(d\left(x_{n-1}, x_{n}\right)\right) .
$$

If $P\left(x_{n-1}, x_{n}\right)=\frac{d\left(x_{n-1}, x_{n}\right)\left[1+d\left(x_{n}, x_{n+1}\right)\right]}{1+d\left(x_{n-1}, x_{n}\right)}$, then inequality (2.19) becomes

$$
\begin{aligned}
d\left(x_{n-1}, x_{n}\right)\left[1+d\left(x_{n}, x_{n+1}\right)\right] & \leq \psi\left(d\left(x_{n-1}, x_{n}\right)\right)\left[1+d\left(x_{n-1}, x_{n}\right)\right] \\
& =\psi\left(d\left(x_{n-1}, x_{n}\right)\right)+\psi\left(d\left(x_{n-1}, x_{n}\right)\right) d\left(x_{n-1}, x_{n}\right) \\
& <d\left(x_{n-1}, x_{n}\right)+\psi\left(d\left(x_{n-1}, x_{n}\right)\right) d\left(x_{n-1}, x_{n}\right) .
\end{aligned}
$$

The required simplification implies (2.20). In other words, for any possibilities in $P\left(x_{n-1}\right.$, $x_{n}$ ), inequality (2.19) yields inequality (2.20). Recursively, we get that

$$
d\left(x_{n+1}, x_{n}\right) \leq \psi\left(d\left(x_{n}, x_{n-1}\right)\right)<d\left(x_{n}, x_{n-1}\right) \quad \text { and } \quad d\left(x_{n+1}, x_{n}\right)<\psi^{n}\left(d\left(x_{1}, x_{0}\right)\right) \quad \text { for all } n
$$

Due to the observation above, we notice that the sequence $\left\{d\left(x_{n}, x_{n+1}\right)\right\}$ is nonincreasing. As the next step, we shall indicate that the sequence $\left\{x_{n}\right\}$ has no periodic point, that is,

$$
x_{n} \neq x_{n+k} \quad \text { for all } k \in \mathbb{N} \text { and for all } n \in \mathbb{N}_{0} \text {. }
$$


Indeed, if $x_{n}=x_{n+k}$ for some $n \in \mathbb{N}_{0}$ and $k \in \mathbb{N}$, we find $x_{n+1}=T x_{n}=T x_{n+k}=x_{n+k+1}$. On account of the observations and estimations above, we have $P\left(x_{n-1}, x_{n}\right)=d\left(x_{n}, x_{n+1}\right)$. Thus, by taking inequalities (2.8) and (2.3) into account, we find that

$$
\begin{aligned}
d\left(x_{n}, x_{n+1}\right) & =P\left(x_{n-1}, x_{n}\right)-a Q\left(x_{n-1}, x_{n}\right) \leq \psi\left(R\left(x_{n-1}, x_{n}\right)\right) \\
& \leq \psi\left(R\left(x_{n+k-1}, x_{n+k}\right)\right) \\
& \leq \psi\left(d\left(x_{n+k-1}, x_{n+k}\right)\right) \\
& \leq \psi^{k-1}\left(d\left(x_{n}, x_{n+1}\right)\right)<d\left(x_{n}, x_{n+1}\right),
\end{aligned}
$$

a contradiction. As a result, we suppose that

$$
x_{n} \neq x_{m} \quad \text { for all distinct } n, m \in \mathbb{N} \text {. }
$$

A verbatim repetition of the related lines in the proof of Theorem 10 completes the proof.

Corollary 16 Let $T$ be an orbitally continuous self-map on the T-orbitally complete $b$ $B M S(X, d)$. Suppose that there exist $q \in[0,1)$ and $a \geq 0$ such that

$$
P(x, y)-a Q(x, y) \leq q R(x, y)
$$

for all distinct $x, y \in X$, where $P(x, y), Q(x, y), R(x, y)$ are defined as in Theorem 15. Then, for each $x_{0} \in X$, the sequence $\left\{T^{n} x_{0}\right\}_{n \in \mathbb{N}}$ converges to a fixed point of $T$.

Corollary 17 Let $T$ be an orbitally continuous self-map on the T-orbitally complete $b$ $B M S(X, d)$. Suppose that there exist $q \in[0,1)$ and $a \geq 0$ such that

$$
\min \{d(T x, T y), d(x, y), d(x, T x), d(y, T y)\}-a Q(x, y) \leq q R(x, y)
$$

for $x, y \in X$, where $Q(x, y), R(x, y)$ are defined as in Theorem 15. Then, for each $x_{0} \in X$, the sequence $\left\{T^{n} x_{0}\right\}_{n \in \mathbb{N}}$ converges to a fixed point of $T$.

Corollary 18 Let $T$ be an orbitally continuous self-map on the T-orbitally complete $b$ $B M S(X, d)$. Suppose that there exist $k, p \in[0,1)$ with $k+p<1$ and $a \geq 0$ such that

$$
\min \{d(T x, T y), d(x, y), d(x, T x), d(y, T y)\}-a Q(x, y) \leq k d(x, y)+p d(x, T x)
$$

for $x, y \in X$, where $Q(x, y), R(x, y)$ are defined as in Theorem 15. Then, for each $x_{0} \in X$, the sequence $\left\{T^{n} x_{0}\right\}_{n \in \mathbb{N}}$ converges to a fixed point of $T$.

Corollary 19 Let $T$ be an orbitally continuous self-map on the T-orbitally complete BMS $(X, d)$. Suppose that there exist $\psi \in \Psi$ and $a \geq 0$ such that

$$
P(x, y)-a Q(x, y) \leq \psi(R(x, y))
$$

for all distinct $x, y \in X$, where $P(x, y), Q(x, y), R(x, y)$ are defined as in Theorem 15. Then, for each $x_{0} \in X$, the sequence $\left\{T^{n} x_{0}\right\}_{n \in \mathbb{N}}$ converges to a fixed point of $T$. 
Corollary 20 Let $T$ be an orbitally continuous self-map on the T-orbitally complete BMS $(X, d)$. Suppose that there exist $q \in[0,1)$ and $a \geq 0$ such that

$$
P(x, y)-a Q(x, y) \leq q R(x, y)
$$

for all distinct $x, y \in X$, where $P(x, y), Q(x, y), R(x, y)$ are defined as in Theorem 15. Then, for each $x_{0} \in X$, the sequence $\left\{T^{n} x_{0}\right\}_{n \in \mathbb{N}}$ converges to a fixed point of $T$.

Corollary 21 Let $T$ be an orbitally continuous self-map on the T-orbitally complete BMS $(X, d)$. Suppose that there exist $q \in[0,1)$ and $a \geq 0$ such that

$$
\min \{d(T x, T y), d(x, y), d(x, T x), d(y, T y)\}-a Q(x, y) \leq q R(x, y)
$$

for $x, y \in X$, where $Q(x, y), R(x, y)$ are defined as in Theorem 15. Then, for each $x_{0} \in X$, the sequence $\left\{T^{n} x_{0}\right\}_{n \in \mathbb{N}}$ converges to a fixed point of $T$.

Corollary 22 Let $T$ be an orbitally continuous self-map on the T-orbitally complete BMS $(X, d)$. Suppose that there exist $k, p \in[0,1)$ with $k+p<1$ and $a \geq 0$ such that

$$
\min \{d(T x, T y), d(x, y), d(x, T x), d(y, T y)\}-a Q(x, y) \leq k d(x, y)+p d(x, T x)
$$

for $x, y \in X$, where $Q(x, y), R(x, y)$ are defined as in Theorem 15. Then, for each $x_{0} \in X$, the sequence $\left\{T^{n} x_{0}\right\}_{n \in \mathbb{N}}$ converges to a fixed point of $T$.

Theorem 23 Let $T$ be an orbitally continuous self-map on the T-orbitally complete b-BMS $(X, d)$. Suppose that there exist $\psi \in \Psi$ and $a \geq 0$ such that

$$
K(x, y)-a Q(x, y) \leq \psi(S(x, y))
$$

for all distinct $x, y \in X$, where

$$
\begin{aligned}
& K(x, y)=\min \{d(T x, T y), d(y, T y)\}, \\
& Q(x, y)=\min \{d(x, T y), d(y, T x)\}, \\
& S(x, y)=\max \{d(x, y), d(x, T x), d(y, T y)\} .
\end{aligned}
$$

Then, for each $x_{0} \in X$, the sequence $\left\{T^{n} x_{0}\right\}_{n \in \mathbb{N}}$ converges to a fixed point of $T$.

Proof We use the same construction as in Theorem 10 to get an iterative sequence $\left\{x_{n}=\right.$ $\left.T x_{n-1}\right\}_{n \in \mathbb{N}}$, with an arbitrary initial value $x_{0}:=x \in X$. Repeating the same arguments in the proof of Theorem 10, we derive that adjacent terms of the sequence $\left\{x_{n}\right\}$ are distinct, that is,

$$
x_{n} \neq x_{n-1} \quad \text { for all } n \in \mathbb{N} \text {. }
$$

For $x=x_{n-1}$ and $y=x_{n}$, inequality (2.24) infers that

$$
K\left(x_{n-1}, x_{n}\right)-a Q\left(x_{n-1}, x_{n}\right) \leq \psi\left(S\left(x_{n-1}, x_{n}\right)\right)
$$


where

$$
\begin{aligned}
K\left(x_{n-1}, x_{n}\right) & =\min \left\{d\left(T x_{n-1}, T x_{n}\right), d\left(x_{n}, T x_{n}\right)\right\}=d\left(x_{n}, x_{n+1}\right), \\
Q\left(x_{n-1}, x_{n}\right) & =\min \left\{d\left(x_{n-1}, T x_{n}\right) d\left(x_{n}, T x_{n-1}\right)\right\}=0, \\
S\left(x_{n-1}, x_{n}\right) & =\min \left\{d\left(x_{n-1}, x_{n}\right), d\left(x_{n-1}, T x_{n-1}\right), d\left(x_{n}, T x_{n}\right)\right\} \\
& =\min \left\{d\left(x_{n-1}, x_{n}\right), d\left(x_{n}, x_{n+1}\right)\right\} .
\end{aligned}
$$

Since $\psi(t)<t$ for all $t>0$, the case $S\left(x_{n-1}, x_{n}\right)=d\left(x_{n}, x_{n+1}\right)$ is impossible. More precisely, it is the case, inequality (2.25) turns into

$$
d\left(x_{n}, x_{n+1}\right) \leq \psi d\left(x_{n}, x_{n+1}\right)<d\left(x_{n}, x_{n+1}\right)
$$

a contradiction. Hence, inequality (2.25) yields that

$$
d\left(x_{n}, x_{n+1}\right) \leq \psi d\left(x_{n-1}, x_{n}\right)<d\left(x_{n-1}, x_{n}\right) \quad \text { and } \quad d\left(x_{n}, x_{n+1}\right) \leq \psi^{n} d\left(x_{0}, x_{1}\right)
$$

for all $n \in \mathbb{N}$.

Hence, we conclude that the sequence $\left\{d\left(x_{n}, x_{n+1}\right)\right\}$ is nonincreasing. In what follows we show that the iterative sequence $\left\{x_{n}\right\}$ has no periodic point, that is,

$$
x_{n} \neq x_{n+k} \quad \text { for all } k \in \mathbb{N} \text { and for all } n \in \mathbb{N}_{0} .
$$

Indeed, if $x_{n}=x_{n+k}$ for some $n \in \mathbb{N}_{0}$ and $k \in \mathbb{N}$, we have $x_{n+1}=T x_{n}=T x_{n+k}=x_{n+k+1}$. Based on the observations above, we obtain that $K\left(x_{n-1}, x_{n}\right)=d\left(x_{n}, x_{n+1}\right)$. Consequently, inequalities (2.26) and (2.24) imply that

$$
\begin{aligned}
d\left(x_{n}, x_{n+1}\right) & =K\left(x_{n-1}, x_{n}\right)-a Q\left(x_{n-1}, x_{n}\right) \leq \psi\left(S\left(x_{n-1}, x_{n}\right)\right) \\
& \leq \psi\left(S\left(x_{n+k-1}, x_{n+k}\right)\right) \\
& \leq \psi\left(d\left(x_{n+k-1}, x_{n+k}\right)\right) \\
& \leq \psi^{k-1}\left(d\left(x_{n}, x_{n+1}\right)\right)<d\left(x_{n}, x_{n+1}\right),
\end{aligned}
$$

which is a contradiction. Hence, we assume that

$$
x_{n} \neq x_{m} \quad \text { for all distinct } n, m \in \mathbb{N} \text {. }
$$

A verbatim repetition of the related lines in the proof of Theorem 10 completes the proof.

Corollary 24 Let $T$ be an orbitally continuous self-map on the T-orbitally complete b$B M S(X, d)$. Suppose that there exist $q \in[0,1)$ and $a \geq 0$ such that

$$
K(x, y)-a Q(x, y) \leq q S(x, y)
$$

for all distinct $x, y \in X$, where $K(x, y), Q(x, y), S(x, y)$ are defined as in Theorem 23. Then, for each $x_{0} \in X$, the sequence $\left\{T^{n} x_{0}\right\}_{n \in \mathbb{N}}$ converges to a fixed point of $T$. 
Corollary 25 Let $T$ be an orbitally continuous self-map on the T-orbitally complete $b$ $B M S(X, d)$. Suppose that there exist $k, p, r \in[0,1)$ with $k+p+r<1$ and $a \geq 0$ such that

$$
K(x, y)-a Q(x, y) \leq k d(x, y)+p d(x, T x)+r d(x, T x)
$$

for $x, y \in X$, where $K(x, y), Q(x, y)$ are defined as in Theorem 23. Then, for each $x_{0} \in X$, the sequence $\left\{T^{n} x_{0}\right\}_{n \in \mathbb{N}}$ converges to a fixed point of $T$.

Corollary 26 Let $T$ be an orbitally continuous self-map on the T-orbitally complete BMS $(X, d)$. Suppose that there exist $\psi \in \Psi$ and $a \geq 0$ such that

$$
K(x, y)-a Q(x, y) \leq \psi(S(x, y))
$$

for all distinct $x, y \in X$, where $K(x, y), Q(x, y), S(x, y)$ are defined as in Theorem 23. Then, for each $x_{0} \in X$, the sequence $\left\{T^{n} x_{0}\right\}_{n \in \mathbb{N}}$ converges to a fixed point of $T$.

Corollary 27 Let $T$ be an orbitally continuous self-map on the T-orbitally complete BMS $(X, d)$. Suppose that there exist $q \in[0,1)$ and $a \geq 0$ such that

$$
K(x, y)-a Q(x, y) \leq q R S(x, y)
$$

for all distinct $x, y \in X$, where $K(x, y), Q(x, y), S(x, y)$ are defined as in Theorem 23. Then, for each $x_{0} \in X$, the sequence $\left\{T^{n} x_{0}\right\}_{n \in \mathbb{N}}$ converges to a fixed point of $T$.

Corollary 28 Let $T$ be an orbitally continuous self-map on the T-orbitally complete BMS $(X, d)$. Suppose that there exist $k, p, r \in[0,1)$ with $k+p+r<1$ and $a \geq 0$ such that

$$
K(x, y)-a Q(x, y) \leq k d(x, y)+p d(x, T x)+r d(y, T y)
$$

for $x, y \in X$, where $K(x, y), Q(x, y)$ are defined as in Theorem 23. Then, for each $x_{0} \in X$, the sequence $\left\{T^{n} x_{0}\right\}_{n \in \mathbb{N}}$ converges to a fixed point of $T$.

\subsection{Achari type nonunique fixed point results [3]}

Theorem 29 Let $T$ be an orbitally continuous self-map on the T-orbitally complete b-BMS $(X, d)$. Suppose that there exists $\psi \in \Psi$ such that

$$
\frac{A(x, y)-B(x, y)}{C(x, y)} \leq \psi(d(x, y))
$$

for all $x, y \in X$, where

$$
\begin{aligned}
& A(x, y)=\min \{d(T x, T y) d(x, y), d(x, T x) d(y, T y)\}, \\
& B(x, y)=\min \{d(x, T x) d(x, T y), d(y, T y) d(T x, y)\}, \\
& C(x, y)=\min \{d(x, T x), d(y, T y)\}
\end{aligned}
$$

with $R(x, y) \neq 0$. Then, for each $x_{0} \in X$, the sequence $\left\{T^{n} x_{0}\right\}_{n \in \mathbb{N}}$ converges to a fixed point of $T$. 
Proof By following line by line the proof of Theorem 10, we construct an iterative sequence $\left\{x_{n}=T x_{n-1}\right\}_{n \in \mathbb{N}}$ starting from an arbitrary initial value $x_{0}:=x \in X$. Regarding the discussion in the proof of Theorem 10, we know that the terms of the sequence $\left\{x_{n}\right\}$ are distinct, that is,

$$
x_{n} \neq x_{n-1} \quad \text { for all } n \in \mathbb{N} \text {. }
$$

Employing inequality (2.29), by taking $x=x_{n-1}$ and $y=x_{n}$ in, we attain that

$$
\frac{A\left(x_{n-1}, x_{n}\right)-B\left(x_{n-1}, x_{n}\right)}{C\left(x_{n-1}, x_{n}\right)} \leq \psi\left(d\left(x_{n-1}, x_{n}\right)\right),
$$

where

$$
\begin{aligned}
& A\left(x_{n-1}, x_{n}\right)=\min \left\{d\left(T x_{n-1}, T x_{n}\right) d\left(x_{n-1}, x_{n}\right), d\left(x_{n-1}, T x_{n-1}\right) d\left(x_{n}, T x_{n}\right)\right\}, \\
& B\left(x_{n-1}, x_{n}\right)=\min \left\{d\left(x_{n-1}, T x_{n-1}\right) d\left(x_{n-1}, T x_{n}\right), d\left(x_{n}, T x_{n}\right) d\left(T x_{n-1}, x_{n}\right)\right\}, \\
& C\left(x_{n-1}, x_{n}\right)=\min \left\{d\left(x_{n-1}, T x_{n-1}\right), d\left(x_{n}, T x_{n}\right)\right\} .
\end{aligned}
$$

On account of $b$-BMS, we simplify the above inequality as follows:

$$
\frac{d\left(x_{n}, x_{n+1}\right) d\left(x_{n-1}, x_{n}\right)}{\min \left\{d\left(x_{n-1}, x_{n}\right), d\left(x_{n}, x_{n+1}\right)\right\}} \leq \psi\left(d\left(x_{n-1}, x_{n}\right)\right) \text {. }
$$

Notice that for the case $\min \left\{d\left(x_{n-1}, x_{n}\right), d\left(x_{n}, x_{n+1}\right)\right\}=d\left(x_{n}, x_{n+1}\right)$, inequality (2.30) turns into

$$
d\left(x_{n-1}, x_{n}\right) \leq \psi\left(d\left(x_{n-1}, x_{n}\right)\right)<d\left(x_{n-1}, x_{n}\right),
$$

a contraction (since $\psi(t)<t$ for all $t>0$ ). Accordingly, we conclude that

$$
d\left(x_{n}, x_{n+1}\right) \leq \psi\left(d\left(x_{n-1}, x_{n}\right)\right)
$$

Recursively, we get

$$
d\left(x_{n}, x_{n+1}\right) \leq \psi\left(d\left(x_{n-1}, x_{n}\right)\right) \leq \psi^{2}\left(d\left(x_{n-2}, x_{n-1}\right)\right) \leq \cdots \leq \psi^{n}\left(d\left(x_{0}, x_{1}\right)\right) .
$$

Due to the definition of comparison function, we have

$$
\lim _{n \rightarrow \infty} d\left(x_{n+1}, x_{n}\right)=0
$$

Furthermore, one can easily show that the sequence $\left\{x_{n}\right\}$ has no periodic point, that is,

$$
x_{n} \neq x_{n+k} \quad \text { for all } k \in \mathbb{N} \text { and for all } n \in \mathbb{N}_{0} \text {. }
$$

Indeed, if $x_{n}=x_{n+k}$ for some $n \in \mathbb{N}_{0}$ and $k \in \mathbb{N}$, we get $x_{n+1}=T x_{n}=T x_{n+k}=x_{n+k+1}$. On account of (2.31), we derive that

$$
d\left(x_{n}, x_{n+1}\right)=d\left(x_{n+k}, x_{n+k+1}\right) \leq \psi^{k}\left(d\left(x_{n}, x_{n+1}\right)\right)<d\left(x_{n}, x_{n+1}\right),
$$


a contradiction. Accordingly, we suppose that

$$
x_{n} \neq x_{m} \quad \text { for all distinct } n, m \in \mathbb{N} \text {. }
$$

A verbatim repetition of the related lines in the proof of Theorem 10 completes the proof.

Corollary 30 Let $T$ be an orbitally continuous self-map on the T-orbitally complete $b$ $B M S(X, d)$. Suppose that there exists $\psi \in \Psi$ such that

$$
\frac{A(x, y)-B(x, y)}{C(x, y)} \leq \psi(d(x, y))
$$

for all $x, y \in X$, where $A(x, y), B(x, y), C(x, y)$ are defined as in Theorem 29. Then, for each $x_{0} \in X$, the sequence $\left\{T^{n} x_{0}\right\}_{n \in \mathbb{N}}$ converges to a fixed point of $T$.

The following is an immediate consequence of Theorem 29 by letting $\psi(t)=q t$, where $q \in[0,1)$.

Corollary 31 Let $T$ be an orbitally continuous self-map on the T-orbitally complete $b$ $B M S(X, d)$. Suppose that there exists $q \in[0,1)$ such that

$$
\frac{A(x, y)-B(x, y)}{C(x, y)} \leq q d(x, y)
$$

for all $x, y \in X$, where $A(x, y), B(x, y), C(x, y)$ are defined as in Theorem 29. Then, for each $x_{0} \in X$, the sequence $\left\{T^{n} x_{0}\right\}_{n \in \mathbb{N}}$ converges to a fixed point of $T$.

The following is an immediate consequence of Theorem 29 by letting $s=1$.

Corollary 32 Let $T$ be an orbitally continuous self-map on the T-orbitally complete BMS $(X, d)$. Suppose that there exists $\psi \in \Psi$ such that

$$
\frac{A(x, y)-B(x, y)}{C(x, y)} \leq \psi(d(x, y))
$$

for all $x, y \in X$, where $A(x, y), B(x, y), C(x, y)$ are defined as in Theorem 29. Then, for each $x_{0} \in X$, the sequence $\left\{T^{n} x_{0}\right\}_{n \in \mathbb{N}}$ converges to a fixed point of $T$.

The following is an immediate consequence of Corollary 32 by letting $\psi(t)=q t$, where $q \in[0,1)$.

Corollary 33 Let $T$ be an orbitally continuous self-map on the T-orbitally complete BMS $(X, d)$. Suppose that there exists $q \in[0,1)$ such that

$$
\frac{A(x, y)-B(x, y)}{C(x, y)} \leq q d(x, y)
$$

for all $x, y \in X$, where $A(x, y), B(x, y), C(x, y)$ are defined as in Theorem 29. Then, for each $x_{0} \in X$, the sequence $\left\{T^{n} x_{0}\right\}_{n \in \mathbb{N}}$ converges to a fixed point of $T$. 


\subsection{Pachpatte type nonunique fixed point results [2]}

Theorem 34 Let $T$ be an orbitally continuous self-map on the T-orbitally complete $b$ $B M S(X, d)$. Suppose that there exists $\psi \in \Psi$ such that

$$
m(x, y)-n(x, y) \leq \psi(d(x, T x) d(y, T y))
$$

for all $x, y \in X$, where

$$
\begin{aligned}
& m(x, y)=\min \left\{[d(T x, T y)]^{2}, d(x, y) d(T x, T y),[d(y, T y)]^{2}\right\}, \\
& n(x, y)=\min \{d(x, T x) d(y, T y), d(x, T y) d(y, T x)\}
\end{aligned}
$$

with $R(x, y) \neq 0$. Then, for each $x_{0} \in X$, the sequence $\left\{T^{n} x_{0}\right\}_{n \in \mathbb{N}}$ converges to a fixed point of $T$.

Proof Again by following line by line the proof of Theorem 10, we construct an iterative sequence $\left\{x_{n}=T x_{n-1}\right\}_{n \in \mathbb{N}}$ whose terms are distinct from each other, by starting from an arbitrary initial value $x_{0}:=x \in X$.

Utilizing inequality (2.39) for $x=x_{n-1}$ and $y=x_{n}$, we obtain that

$$
m\left(x_{n-1}, x_{n}\right)-n\left(x_{n-1}, x_{n}\right) \leq \psi\left(d\left(x_{n-1}, T x_{n-1}\right) d\left(x_{n}, T x_{n}\right)\right)
$$

where

$$
\begin{aligned}
& m\left(x_{n-1}, x_{n}\right)=\min \left\{\left[d\left(T x_{n-1}, T x_{n}\right)\right]^{2}, d\left(x_{n-1}, x_{n}\right) d\left(T x_{n-1}, T x_{n}\right),\left[d\left(x_{n}, T x_{n}\right)\right]^{2}\right\} \\
& n\left(x_{n-1}, x_{n}\right)=\min \left\{d\left(x_{n-1}, T x_{n-1}\right) d\left(x_{n}, T x_{n}\right), d\left(x_{n-1}, T x_{n}\right) d\left(x_{n}, T x_{n-1}\right)\right\}
\end{aligned}
$$

By simplifying the inequality above, we find that

$$
m\left(x_{n-1}, x_{n}\right) \leq \psi\left(d\left(x_{n-1}, x_{n}\right) d\left(x_{n}, x_{n+1}\right)\right)
$$

where

$$
m\left(x_{n-1}, x_{n}\right)=\min \left\{\left[d\left(x_{n}, x_{n+1}\right)\right]^{2}, d\left(x_{n-1}, x_{n}\right) d\left(x_{n}, x_{n+1}\right)\right\} .
$$

It is clear that the case

$$
m\left(x_{n-1}, x_{n}\right)=d\left(x_{n-1}, x_{n}\right) d\left(x_{n}, x_{n+1}\right)
$$

is not possible. If it were the case, inequality (2.40) would turn into

$$
d\left(x_{n-1}, x_{n}\right) d\left(x_{n}, x_{n+1}\right) \leq \psi\left(d\left(x_{n-1}, x_{n}\right) d\left(x_{n}, x_{n+1}\right)\right)<d\left(x_{n-1}, x_{n}\right) d\left(x_{n}, x_{n+1}\right)
$$

a contraction (since $\psi(t)<t$ for all $t>0$ ). Consequently, we derive

$$
\left[d\left(x_{n}, x_{n+1}\right)\right]^{2} \leq \psi\left(d\left(x_{n-1}, x_{n}\right) d\left(x_{n}, x_{n+1}\right)\right)<d\left(x_{n-1}, x_{n}\right) d\left(x_{n}, x_{n+1}\right),
$$


which yields

$$
d\left(x_{n}, x_{n+1}\right)<d\left(x_{n-1}, x_{n}\right) .
$$

Regarding the fact that $\psi$ is nondecreasing, and combining inequalities (2.43) and (2.44), we obtain that

$$
\left[d\left(x_{n}, x_{n+1}\right)\right]^{2} \leq \psi\left(d\left(x_{n-1}, x_{n}\right) d\left(x_{n}, x_{n+1}\right)\right)<\psi\left(\left[d\left(x_{n-1}, x_{n}\right)\right]^{2}\right) .
$$

Iteratively, we get that

$$
\left[d\left(x_{n}, x_{n+1}\right)\right]^{2} \leq \psi\left(\left[d\left(x_{n-1}, x_{n}\right)\right]^{2}\right) \leq \psi^{2}\left(\left[d\left(x_{n-2}, x_{n-1}\right)\right]^{2}\right) \leq \cdots \leq \psi^{n}\left(\left[d\left(x_{0}, x_{1}\right)\right]^{2}\right) .
$$

Hence, we have

$$
\lim _{n \rightarrow \infty}\left[d\left(x_{n+1}, x_{n}\right)\right]^{2}=0 \quad \Longleftrightarrow \quad \lim _{n \rightarrow \infty} d\left(x_{n+1}, x_{n}\right)=0
$$

The rest of the proof is a verbatim repetition of the related lines in the proof of Theorem 10.

If we take $\psi(t)=q t$, then Theorem 34 implies the following result.

Corollary 35 Let $T$ be an orbitally continuous self-map on the T-orbitally complete $b$ $B M S(X, d)$. Suppose that there exists $q \in[0,1)$ such that

$$
m(x, y)-n(x, y) \leq q d(x, T x) d(y, T y)
$$

for all $x, y \in X$, where $m(x, y)$ and $n(x, y)$ are defined as in Theorem 34. Then, for each $x_{0} \in X$, the sequence $\left\{T^{n} x_{0}\right\}_{n \in \mathbb{N}}$ converges to a fixed point of $T$.

If the statements of Theorem 34 are considered in the setting of BMS instead of $b$-BMS, we get the following consequence.

Corollary 36 Let $T$ be an orbitally continuous self-map on the T-orbitally complete BMS $(X, d)$. Suppose that there exists $\psi \in \Psi$ such that

$$
m(x, y)-n(x, y) \leq \psi(d(x, T x) d(y, T y))
$$

for all $x, y \in X$, where $m(x, y)$ and $n(x, y)$ are defined as in Theorem 34. For each $x_{0} \in X$, the sequence $\left\{T^{n} x_{0}\right\}_{n \in \mathbb{N}}$ converges to a fixed point of $T$.

If we take $\psi(t)=q t$ in Corollary 36, then the following consequence is obtained immediately.

Corollary 37 Let $T$ be an orbitally continuous self-map on the T-orbitally complete BMS $(X, d)$. Suppose that there exists $q \in[0,1)$ such that

$$
m(x, y)-n(x, y) \leq q d(x, T x) d(y, T y)
$$


for all $x, y \in X$, where $m(x, y)$ and $n(x, y)$ are defined as in Theorem 34. Then, for each $x_{0} \in X$, the sequence $\left\{T^{n} x_{0}\right\}_{n \in \mathbb{N}}$ converges to a fixed point of $T$.

\subsection{Karapınar type nonunique fixed point results [28]}

Theorem 38 Let $T$ be an orbitally continuous self-map on the T-orbitally complete $b$-BMS $(X, d)$. Suppose that there exist real numbers $a_{1}, a_{2}, a_{3}, a_{4}, a_{5}$ and a self-mapping $T: X \rightarrow X$ satisfies the conditions

$$
\begin{aligned}
& 0 \leq \frac{a_{4}-a_{2}}{a_{1}+a_{2}}<1, \quad a_{1}+a_{2} \neq 0, \quad a_{1}+a_{2}+a_{3}>0 \quad \text { and } 0 \leq a_{3}-a_{5} \\
& a_{1} d(T x, T y)+a_{2}[d(x, T x)+d(y, T y)]+a_{3}[d(y, T x)+d(x, T y)] \\
& \quad \leq a_{4} d(x, y)+a_{5} d\left(x, T^{2} x\right)
\end{aligned}
$$

hold for all $x, y \in X$. Then $T$ has at least one fixed point.

Proof For arbitrary $x_{0} \in X$, we shall construct a sequence $\left\{x_{n}\right\}$ as follows:

$$
x_{n+1}:=T x_{n}, \quad n=0,1,2, \ldots
$$

Utilizing the inequality by taking $x=x_{n}$ and $y=x_{n+1}$, we find that

$$
\begin{aligned}
& a_{1} d\left(T x_{n}, T x_{n+1}\right)+a_{2}\left[d\left(x_{n}, T x_{n}\right)+d\left(x_{n+1}, T x_{n+1}\right)\right]+a_{3}\left[d\left(x_{n+1}, T x_{n}\right)+d\left(x_{n}, T x_{n+1}\right)\right] \\
& \quad \leq a_{4} d\left(x_{n}, x_{n+1}\right)+a_{5} d\left(x_{n}, T^{2} x_{n}\right)
\end{aligned}
$$

for all $a_{1}, a_{2}, a_{3}, a_{4}, a_{5}$, which fulfils (2.49). On account of (2.51), statement (2.52) becomes

$$
\begin{aligned}
& a_{1} d\left(x_{n+1}, x_{n+2}\right)+a_{2}\left[d\left(x_{n}, x_{n+1}\right)+d\left(x_{n+1}, x_{n+2}\right)\right]+a_{3}\left[d\left(x_{n+1}, x_{n+1}\right)+d\left(x_{n}, x_{n+2}\right)\right] \\
& \quad \leq a_{4} d\left(x_{n}, x_{n+1}\right)+a_{5} d\left(x_{n}, x_{n+2}\right) .
\end{aligned}
$$

By a simple computation, we derive

$$
\left(a_{1}+a_{2}\right) d\left(x_{n+1}, x_{n+2}\right)+\left(a_{3}-a_{5}\right) d\left(x_{n}, x_{n+2}\right) \leq\left(a_{4}-a_{2}\right) d\left(x_{n}, x_{n+1}\right) .
$$

So, the inequality above yields that

$$
d\left(x_{n+1}, x_{n+2}\right) \leq q d\left(x_{n}, x_{n+1}\right)
$$

where $q=\frac{a_{4}-a_{2}}{a_{1}+a_{2}}$. Due to (2.49), we have $0 \leq q<1$. Regarding (2.55), we recursively obtain

$$
d\left(x_{n}, x_{n+1}\right) \leq q d\left(x_{n-1}, x_{n}\right) \leq q^{2} d\left(x_{n-2}, x_{n-1}\right) \leq \cdots \leq q^{n} d\left(x_{0}, x_{1}\right) .
$$

Thus, the sequence $\left\{d\left(x_{n}, x_{n+1}\right)\right\}$ is nonincreasing.

In what follows we shall prove that the sequence $\left\{x_{n}\right\}$ has no periodic point, that is,

$$
x_{n} \neq x_{n+k} \quad \text { for all } k \in \mathbb{N} \text { and for all } n \in \mathbb{N}_{0} \text {. }
$$


Actually, if $x_{n}=x_{n+k}$ for some $n \in \mathbb{N}_{0}$ and $k \in \mathbb{N}$, we find $x_{n+1}=T x_{n}=T x_{n+k}=x_{n+k+1}$. Keeping inequality (2.55) in mind, we derive that

$$
d\left(x_{n}, x_{n+1}\right)=d\left(x_{n+k}, x_{n+k+1}\right) \leq q^{k} d\left(x_{n}, x_{n+1}\right),
$$

which is a contradiction. Consequently, we suppose that

$$
x_{n} \neq x_{m} \quad \text { for all distinct } n, m \in \mathbb{N} \text {. }
$$

One can easily discover that $x_{n+k} \neq x_{m+k}$ for all distinct $n, m \in \mathbb{N}$ and $x_{n+k}, x_{m+k} \in X \backslash$ $\left\{x_{n}, x_{m}\right\}$.

There exists a natural number $M$ such that

$$
0<q^{k} s<1 \text { for all } k \geq M \text {, }
$$

since $k \in[0,1)$ and hence $\lim _{n \rightarrow \infty} k^{n}=0$.

As a next step, we shall indicate that $\left\{x_{n}\right\}$ is a Cauchy sequence. By regarding the modified quadrilateral inequality, we find

$$
\begin{aligned}
d\left(x_{m}, x_{n}\right) & \leq s\left[d\left(x_{m}, x_{m+k}\right)+d\left(x_{m+k}, x_{n+k}\right)+d\left(x_{n+k}, x_{n}\right)\right] \\
& \leq s q^{m} d\left(x_{0}, x_{k}\right)+s q^{k} d\left(x_{m}, x_{n}\right)+s q^{n} d\left(x_{k}, x_{0}\right) .
\end{aligned}
$$

By rearranging the term in the inequality above, we attain that

$$
d\left(x_{m}, x_{n}\right) \leq \frac{s\left(q^{m}+q^{n}\right)}{1-q^{k} s} d\left(x_{k}, x_{0}\right) .
$$

Consequently, we derive that $\left(x_{n}\right)_{n \in \mathbb{N}}$ is a Cauchy sequence.

The rest of the proof is deduced by following the corresponding lines in the proof of Theorem 10.

Corollary 39 Let $T$ be an orbitally continuous self-map on the T-orbitally complete BMS $(X, d)$. Suppose that there exist real numbers $a_{1}, a_{2}, a_{3}, a_{4}, a_{5}$ and a self-mapping $T: X \rightarrow X$ satisfies the conditions

$$
\begin{aligned}
& 0 \leq \frac{a_{4}-a_{2}}{a_{1}+a_{2}}<1, \quad a_{1}+a_{2} \neq 0, \quad a_{1}+a_{2}+a_{3}>0 \quad \text { and } \quad 0 \leq a_{3}-a_{5} \\
& a_{1} d(T x, T y)+a_{2}[d(x, T x)+d(y, T y)]+a_{3}[d(y, T x)+d(x, T y)] \leq a_{4} d(x, y)+a_{5} d\left(x, T^{2} x\right)
\end{aligned}
$$

hold for all $x, y \in X$. Then $T$ has at least one fixed point.

Proof Take $s=1$ in the proof of Theorem 38 .

The authors appreciate the support of their institutes. 
Authors' contributions

All authors contributed equally and significantly in writing this article. All authors read and approved the final manuscript.

\section{Author details}

'Department of Mathematics, Atilim University, Incek, Ankara, 06836, Turkey. ${ }^{2}$ Nonlinear Analysis and Applied Mathematics (NAAM) Research Group, King Abdulaziz University, Jeddah, 21589, Saudi Arabia. ${ }^{3}$ Texas A\&M University-Kingsville, 700 University Blvd., MSC 172, Kingsville, TX 78363-8202, USA.

\section{Publisher's Note}

Springer Nature remains neutral with regard to jurisdictional claims in published maps and institutional affiliations.

\section{Received: 4 April 2017 Accepted: 11 September 2017 Published online: 15 October 2017}

\section{References}

1. Ćirić, LB: On some maps with a nonunique fixed point. Publ. Inst. Math. 17, 52-58 (1974)

2. Pachpatte, BG: On Ćirić type maps with a nonunique fixed point. Indian J. Pure Appl. Math. 10(8), 1039-1043 (1979)

3. Achari, J: On Ćirić's non-unique fixed points. Mat. Vesn. 13(28), 255-257 (1976)

4. Gupta, S, Ram, B: Non-unique fixed point theorems of Ćirić type. Vijnana Parishad Anusandhan Patrika 41(4), $217-231$ (1998)

5. Liu, Z, Guo, Z, Kang, SM, Lee, SK: On Ćirić type mappings with nonunique fixed and periodic points. Int. J. Pure Appl. Math. 26(3), 399-408 (2006)

6. Liu, ZQ: On Ćirić type mappings with a nonunique coincidence points. Mathematica 35(58), 221-225 (1993)

7. Branciari, A: A fixed point theorem of Banach-Caccioppoli type on a class of generalized metric spaces. Publ. Math. (Debr.) 57, 31-37 (2000)

8. Branciari, A: A fixed point theorem for mappings satisfying a general contractive condition of integral type. Int. J. Math. Math. Sci. 29(9), 531-536 (2002)

9. Aydi, H, Karapınar, E, Samet, B: Fixed points for generalized $(\alpha, \psi)$-contractions on generalized metric spaces. J. Inequal. Appl. 2017, 229 (2014)

10. Aydi, H, Karapınar, E, Lakzian, H: Fixed point results on the class of generalized metric spaces. Math. Sci. 6, 46 (2012)

11. Azam, A, Arshad, M: Kannan fixed point theorems on generalized metric spaces. J. Nonlinear Sci. Appl. 1, 45-48 (2008)

12. Bilgili, N, Karapınar, E: A note on 'common fixed points for $(\psi, \alpha, \beta)$-weakly contractive mappings in generalized metric spaces'. Fixed Point Theory Appl. 2013, 287 (2013)

13. Das, P, Lahiri, BK: Fixed point of a Ljubomir Ćirić's quasi-contraction mapping in a generalized metric space. Publ. Math. (Debr.) 61, 589-594 (2002)

14. Erhan, IM, Karapınar, E, Sekulić, T: Fixed points of $(\psi, \phi)$ contractions on rectangular metric spaces. Fixed Point Theory Appl. 2012, 138 (2012)

15. Jleli, M, Samet, B: The Kannan's fixed point theorem in a cone rectangular metric space. J. Nonlinear Sci. Appl. 2(3), 161-167 (2009)

16. Kadeburg, Z, Radenovic̀, S: On generalized metric spaces: a survey. TWMS J. Pure Appl. Math. 5(1), 3-13 (2014)

17. Karapınar, E: Discussion on $(\alpha, \psi)$ contractions on generalized metric spaces. Abstr. Appl. Anal. 2014 Article ID $962784(2014)$

18. Karapınar, E: Fixed points results for alpha-admissible mapping of integral type on generalized metric spaces. Abstr. Appl. Anal. 2014 Article ID 141409 (2014)

19. Karapınar, E: On $(\alpha, \psi)$ contractions of integral type on generalized metric spaces. In: Mityushevand, V, Ruzhansky, M (eds.) Proceedings of the 9th ISAAC Congress. Springer, Krakow, Poland (2013)

20. Kikina, L, Kikina, K: A fixed point theorem in generalized metric space. Demonstr. Math. XLVI(1), 181-190 (2013)

21. Mihet, D: On Kannan fixed point principle in generalized metric spaces. J. Nonlinear Sci. Appl. 2(2), $92-96$ (2009)

22. Samet, B: Discussion on: a fixed point theorem of Banach-Caccioppoli type on a class of generalized metric spaces by A. Branciari. Publ. Math. (Debr.) 76(4), 493-494 (2010)

23. Suzuki, T: Generalized metric spaces do not have the compatible topology. Abstr. Appl. Anal. 2014, Article ID 458098 (2014)

24. Sarma, IR, Rao, JM, Rao, SS: Contractions over generalized metric spaces. J. Nonlinear Sci. Appl. 2(3), 180-182 (2009)

25. Czerwik, S: Contraction mappings in b-metric spaces. Acta Math. Inform. Univ. Ostrav. 1, 5-11 (1993)

26. George, R, Radenovic, S, Reshma, KP, Shukla, S: Rectangular b-metric space and contraction principles. J. Nonlinear Sci. Appl. 8(6), 1005-1013 (2015)

27. Rus, IA: Generalized Contractions and Applications. Cluj University Press, Cluj-Napoca, Romania (2001)

28. Karapinar, E: A new non-unique fixed point theorem. J. Appl. Funct. Anal. 7(1-2, 92-97 (2012) 